\title{
Sexual Identity Disclosure among Lesbian, Gay, and Bisexual Individuals
}

\author{
Long Doan, ${ }^{a}$ Trenton D. Mize
}

\author{
a) University of Maryland; b) Purdue University
}

Abstract: Most research on sexual prejudice explicitly or implicitly assumes that an individual's sexual orientation identity is known to observers. However, there has been little large-scale survey evidence examining differential rates of disclosure among lesbian, gay, and bisexual (LGB) individuals, and there remains much to be studied as to why and when LGB individuals choose to disclose their sexual identity to others. Using data from a nationally representative sample of LGB Americans ( $N$ $=1,085)$, we assess the contexts and conditions under which LGB individuals disclose their sexual identities. Results show that bisexual women and men are significantly less likely to disclose their sexual identity across several important social domains, such as family and the workplace. This disclosure gap is partially explained by measures of identity commitment but surprisingly not by measures of perceived social acceptance. We discuss implications of these findings for sexuality and identity research.

Keywords: sexual identity; lesbian/gay, bisexual; identity disclosure; stigma; self-authenticity

Citation: Doan, Long, and Trenton D. Mize. 2020. "Sexual Identity Disclosure among Lesbian, Gay, and Bisexual Individuals." Sociological Science 7: 504-527.

Received: August 19, 2020

Accepted: September 19, 2020

Published: October 19, 2020

Editor(s): Jesper Sørensen, Gabriel Rossman

Dol: $10.15195 /$ v7.a21

Copyright: (C) 2020 The Author(s). This open-access article has been published under a Creative Commons Attribution License, which allows unrestricted use, distribution and reproduction, in any form, as long as the original author and source have been credited. (C) (i)
OST research on sexual prejudice explicitly or implicitly assumes that an individual's sexual orientation identity is known to observers. ${ }^{1}$ Yet, decisions about when or if to disclose an LGB sexual identity is an important decision sexual minorities face. Indeed, sexual identity disclosure is considered to be an important part of identity development (Ragins 2004) and self-authenticity (Mason-Schrock 1996). Moreover, even among LGB individuals who are "out" in some domains of their life, sexual minority status has been proposed to be a "concealable stigma" in some arenas (Goffman 1963; Martel 2013; Tilcsik, Anteby, and Knight 2015). ${ }^{2}$ The decision to disclose one's sexual identity to others presents a paradoxical dilemma for sexual minorities (Legate, Ryan, and Weinstein 2012). On the one hand, sexual identity disclosure is related to a variety of mental and physical health benefits (Meyer 2003; Herek et al. 2009). On the other hand, sexual identity nondisclosure and even actively concealing one's identity might be an effective strategy to avoid stigmatization from others (Miller and Major 2000).

Given this inherent trade-off between avoiding negative health consequences from inauthenticity and avoiding stigmatization, this article assesses the contexts and conditions under which lesbian, gay, and bisexual (LGB) individuals disclose their sexual identities. Additionally, we examine whether the predictors of sexual identity disclosure vary by an individual's sexual identity group. In doing so, our results advance understandings of concealable stigma and literatures on identity verification and self-authenticity by examining the trade-off between inauthenticity and stigmatization avoidance. Specifically, we ask: 
1. How do rates of sexual identity disclosure vary between lesbian, gay, and bisexual individuals?

2. What explains differences in rates of sexual identity disclosure?

3. How do these explanations vary by sexual identity group?

\section{Background}

In the following sections, we describe the multidimensionality of sexual orientation and discuss prior research on sexual identity disclosure, self-authenticity, and prejudice toward LGB individuals. Next, using theories of the self and empirical patterns regarding sexual prejudice, we derive hypotheses about why and to what effect sexual identity disclosure varies by sexual identity groups. To test these hypotheses, we analyze data from a nationally representative survey of LGB Americans. Although this data set is one of the best sources of data available to date, it is nevertheless cross sectional. As such, our findings in this article can only speak to correlational relationships between identity, perceived social acceptance, and disclosure. In light of this limitation, we discuss the contributions of this study and implications for future research on stigma, self-authenticity, sexual prejudice, and how their intersections influence individuals' identity disclosures.

\section{Three Ways of Measuring Sexual Orientation}

Sexual orientation encompasses at least three distinct measurable dimensions: identity, behavior, and attraction. Identity refers to how someone would describe their own sexual orientation - of which we focus on heterosexual, bisexual, and gay/lesbian in this article. Behavior refers to a person's sexual practices-with whom they have sexual or romantic relations. Attraction refers to the romantic/sexual attraction a person has to men, women, or both. There is often overlap among these dimensions, but among individuals with some same-sex sexuality (i.e., someone who would describe themselves as LGB, has had sexual encounters with someone of the same sex, or is attracted to someone of the same sex), some discordance among dimensions is more common than complete agreement. That is, individuals often would be classified differently across the dimensions of identity, behavior, and attraction (Laumann et al. 1994; Mize 2015). In this article, we focus on sexual identity, and specifically sexual orientation identity-the public identification or dis-identification with a sexual orientation group.

\section{Differences in Rates of Sexual Identity Disclosure}

Determining rates of sexual identity disclosure is difficult in part because the size of the sexual minority populations is relatively small, making probability samples prohibitively expensive to collect. It is also difficult to determine the rates of sexual identity disclosure because of the multidimensionality of sexual orientation described above. Depending on the dimension of sexuality considered, the size of sexual minority groups can vary greatly (Laumann et al. 1994; Mize 2015). Even 
when focusing on one conceptualization, the method of eliciting self-reports can lead to large differences in estimates of the sexual minority population. In particular, there continues to be a degree of social desirability to direct reports of sexuality, which causes estimates of LGB populations to be incorrectly low (Coffman, Coffman, and Ericson 2017). Nonetheless, current national estimates of the size of the LGB population have varied from 1.7 percent to as large as 7.1 percent (Berg and Lien 2006; Gates 2011).

Because our interests are in sexual orientation identity, we restrict our examination to understanding differences in rates of sexual identity disclosure among those who self-identity as a sexual minority member. Examinations of disclosure among those who might not self-identify, although interesting, speak to different processes that are outside the scope of this article. By focusing on disclosure among those who self-identify as a sexual minority, the problem becomes obtaining correct national estimates of these rates. Past research using convenience samples have shown that bisexual men and women are less likely to disclose their identity to others than gay men and lesbian women (Weinberg, Williams, and Pryor 1994; Rodríguez Rust 2002; Herek et al. 2010), and similar results have been found in larger-scale surveys (Pew Research Center 2013). We build on these findings by examining a wider range of social domains, such as family and the workplace. Therefore, our first hypothesis is as follows:

Hypothesis 1: Across social domains, bisexual men and women will be less likely to disclose their identity to others, compared with gay men and lesbian women

Examining these differences using a national sample allows us to better understand if bisexual men and women's lower disclosure rates has something to do with their sexual minority group and others' perceptions of them or if previous findings are specific to the contexts and populations in which they were examined. Indeed, cohort analyses suggest that same-sex behaviors are seen as more acceptable for women than men (England, Mishel, and Caudillo 2016). There is also a class component of same-sex behaviors for both men and women (Mishel et al. 2020). Just as structural and cultural conditions affect people's sexual behaviors, the normative contexts of the acceptability of same-sex behaviors may influence rates of disclosure for various groups. If we find that the patterns of sexual identity disclosure extend to a national sample and across domains, the key question and a novel contribution of this article becomes why. We draw on the broader literature on self-authenticity to understand the reasons for disclosing one's sexual identity. We argue that perceiving low social acceptance of your identity, past experiences with prejudice, and expectations of negative treatment reduce disclosure rates among LGB individuals. Conversely, a desire for self-authenticity increase disclosure rates. We suggest that whether someone discloses their sexual identity depends partially on the trade-offs between these factors for that person.

\section{Strength of Sexual Identity and Self-Authenticity}

The process of coming out is considered to be one of the key events in sexual identity development for sexual minorities (McLean 2007). Whether and how one 
chooses to come out speaks to issues of identity enactment and feelings of selfauthenticity for sexual minorities (Ragins 2004). Identity theorists have shown that feelings of authenticity are central to the self (Erickson 1995; Hitlin 2003), and feelings of inauthenticity are often linked to worse mental health and negative emotions (Erickson and Wharton 1997). Indeed, for sexual minorities, concealment of sexual identity is related to a variety of negative consequences, including lower relationship satisfaction (Mohr and Fassinger 2006), job dissatisfaction (Ragins, Singh, and Cornwell 2007), and worse mental health (Morris, Waldo, and Rothblum 2001). In other words, one reason LGB people come out is because not doing so can be damaging to one's self.

The extent to which sexual identity concealment is damaging to one's self, however, depends on the strength of identification with one's sexual orientation. Identity theorists have shown individuals seek to verify their identities to the extent that they are important identities to the self (Stets and Trettevik 2014). Drawing on identity theory's concept of identity salience- the probability that an identity will be invoked across situations (Stryker 1980)—scholars have argued that identities that are not salient may be replaced with more salient identities when not confirmed (Burke and Stets 2009). In other words, if people have alternative identities that are more likely to be invoked, they will seek to verify those identities instead of their sexual orientation identity.

Importantly, identity salience as defined in identity theory does not mean subjective importance (Brenner, Serpe, and Stryker 2014). Nevertheless, the two concepts are theoretically similar in many ways (Thoits 2012). Our analyses do include measures of identity importance, but this has been shown to be theoretically distinct and prior to salience (Brenner et al. 2014). As such, we include this measure in the same umbrella of "social integration," which includes both salience and importance. Identity theory argues that the extent to which identities are salient depends on the level of commitment, or structural embeddedness, of the identity (Stryker 1980; Stryker and Burke 2000). This suggests that the more integrated individuals are in their sexual orientation identity groups, the more likely they are to disclose their identity:

Hypothesis 2: LGB individuals will be more likely to disclose their sexual orientation identity if they are highly integrated with other LGB individuals

If high sexual minority integration is positively related to coming out, this raises the possibility that bisexual individuals' lower rates of sexual orientation identity disclosure may be partially due to their lower involvement with other sexual minority members. Indeed, research shows that bisexual individuals are less likely to be involved with (McLean 2008; Thompson 2012) or to feel included in sexual minority communities (Mohr and Rochlen 1999; Hull and Ortyl 2013). Therefore, we might expect that gay men and lesbian women will be more integrated and view their sexual identity as more important than bisexual men and women do. If so, this would partially explain the gap in sexual orientation identity disclosure among groups: 
Hypothesis 3: Level of sexual minority integration will partially mediate the differences in sexual orientation identity disclosure between bisexual men and women and gay men and lesbian women, respectively

\section{Prejudice toward Lesbian, Gay, and Bisexual Individuals}

Identity theories generally view confirmation of one's identities as a positive outcome for mental health and self-esteem. However, recent research shows that confirming highly stigmatized identities may not have the same positive mental health consequences (Thoits 2011, 2016). Therefore, for sexual orientation groups for which there is greater amounts of stigma and prejudice, there may be less benefit in confirming their sexual orientation identity by regularly disclosing it to others (Goffman 1963). Indeed, stigma research finds that perceived discrimination decreases the likelihood of challenging stigma, and internalized stigma increases the likelihood of identity concealment (Thoits and Link 2016). Despite taking a subtler turn (Doan, Loehr, and Miller 2014), sexual prejudice remains a pervasive issue (Herek and McLemore 2013). Prior work suggests that sexual minorities are viewed negatively and generally stigmatized compared with their heterosexual counterparts (Herek 2002; Herek and McLemore 2013). Furthermore, recent evidence suggests that rates of LGB acceptance are likely overstated because of a growing social desirability bias to report positive attitudes about LGB issues (Coffman et al. 2017). Based on stigma theory, we expect that perceived acceptance will be directly related to decisions to disclose an LGB identity:

Hypothesis 4: LGB individuals will be more likely to disclose their sexual orientation identity if they perceive more social acceptance of their sexual identity group

Although much research has focused on gay men and lesbian women or on sexual minorities as an overall group, bisexual men and women have rarely been considered in sociological and social psychological examinations of sexual orientation (Mize 2015, 2016). The work that does explicitly examine attitudes toward bisexual men and women show that they face more acutely negative sentiments than gay men and lesbian women (Herek 2002; Mize and Manago 2018). Several reasons likely underlie these perceptions.

First, Americans tend to believe in monosexism - the idea that people are either exclusively heterosexual or exclusively gay (Bradford 2004). Second, perceptions of choice are inherent to bisexuals' sexual orientation. That is, if someone is romantically interested in men and women then there is a perception that they have some degree of choice in who they are romantically involved with (Mize 2016). Individuals are more likely to discriminate against individuals who they feel have a degree of choice in their stigmatized status (Goffman 1963; Kricheli-Katz 2013). Third, research suggests there are many negative stereotypes of bisexual men and women such as portrayals of bisexual individuals as immature, dishonest, indecisive, disingenuous, promiscuous, and immoral (Yost and Thomas 2012; Mize and Manago 2018).

Although some of these stereotypes are also applied to gay men and lesbian women, Mize and Manago (2018) show that they are more severely applied to 
bisexual men and women. Finally, some have argued that the same-sex marriage movement has contributed to a "secondary marginalization" of bisexual men and women relative to their gay and lesbian counterparts. Indeed, bisexual men and women report feeling left out of the gay rights movement and that they experience biphobia from the movement (Hull and Ortyl 2013). Collectively, these findings suggest that a major reason behind the sexual orientation identity disclosure gap may be in part due to bisexual men and women perceiving less social acceptance relative to their gay and lesbian counterparts. Therefore, we expect:

Hypothesis 5: Level of perceived social acceptance will partially mediate the differences of sexual orientation identity disclosure between bisexual men and women and gay men and lesbian women, respectively

\section{Method}

\section{Data}

To test our hypotheses, we used data from a nationally representative survey of 1,154 LGB US adults collected by the Pew Research Center (2013). ${ }^{3}$ The survey was collected by Pew using GfK's KnowledgePanel in April 2013. Panelists for the GfK panel were recruited using a combination of list-assisted random-digit dial and address-based sample sampling methods. The panel characteristics were benchmarked against the Census' Current Population Survey and is designed to be representative of the US population. The sample was recruited by inviting all self-identified LGBT adults in the panel to participate in the study.

In addition to Pew staff, the instrument was developed with help from leading sexuality scholars from the University of Massachusetts, Amherst and the Williams Institute. The online and anonymous nature of the survey was designed to elicit more honest responses because of the sensitive issues asked about in the survey (Kreuter, Presser, and Tourangeau 2008). Table 1 includes descriptive statistics for the sample. Our primary predictor was a participant's sexual orientation identity. Participants were asked to self-identify as lesbian, gay, or bisexual. These answers were then matched with previous panel responses. If there was a mismatch, participants were asked to reconfirm their current sexual orientation identity before proceeding. In total, there were 262 lesbian women, 390 gay men, 326 bisexual women, and 123 bisexual men in the sample who had no missing values on our dependent measures.

\section{Measures}

Our hypotheses concerned rates of sexual identity disclosure, level of sexual minority integration, and perceived social acceptance among LGB US residents. Table 2 includes descriptive statistics for all key measures (described in text below). Because sexual identity disclosure is contextual (McLean 2007; Orne 2011), we examined it using four outcomes. The first is an overall identity disclosure measure asking participants about how many of the "important" people in their lives are aware of their sexual identity $(1=$ some, most, or all people $) .{ }^{4}$ Two measures asked whether 
Table 1: Sample descriptive statistics $(N=1,085)$.

\begin{tabular}{llc}
\hline \multicolumn{2}{c}{ Definition } & Proportion/Mean \\
\hline $\begin{array}{l}\text { Sexual orientation identity } \\
\text { Lesbian women }\end{array}$ & Participant identifies as lesbian $(1=$ yes $)$ & 0.24 \\
Bisexual women & Participant identifies as a bisexual woman $(1=$ yes $)$ & 0.30 \\
Gay men & Participant identifies as gay $(1=$ yes $)$ & 0.35 \\
Bisexual men & Participant identifies as a bisexual man $(1=$ yes $)$ & 0.11 \\
Age & Participant's age $(21-80)$ & 44.70 \\
& & $(14.82)$ \\
College degree & Participant's highest level of education is at least a Bachelor's & 0.51 \\
& degree & \\
Household income & Household income in thousands of dollars $(10-175)$ & 60.44 \\
& & $(45.98)$ \\
White & & 0.76 \\
Parent & Participant is white $(1=$ yes $)$ & 0.15 \\
Married & Participant is a parent $(1=$ yes $)$ & 0.19 \\
Employed & Participant is married $(1=$ yes $)$ & 0.65 \\
Urban & Currently employed at least part-time & 0.90 \\
Political ideology & Participant lives in a metropolitan area & 3.61 \\
& Participant's political ideology $(1=$ very conservative to 5 = very & $(0.92)$ \\
\hline
\end{tabular}

Note: Standard deviations are in parentheses below means.

participants are out to their mother $(1=$ yes $)$ and whether they are out to their father $(1=$ yes $)$. Finally, participants were asked whether they were out at work $(1=$ some, most, or all coworkers). These measures were dichotomized because the effect of disclosure on discrimination was unlikely to be ordinal in nature (Goffman 1963; Miller and Major 2000; Martell 2013; Tilcsik et al. 2015). We expect the tipping point for when disclosure would have an impact on discrimination experiences to be "some," but in supplementary models using alternative cut points, we found substantively similar results to the ones presented here.

Sexual minority integration was measured using three items. An LGBT involvement index counted the number of LGBT activities the participant has ever participated in. These included being a member of an LGBT organization, attending a rally or march in support of LGBT rights, attending an LGBT pride event, and donating money to politicians or political organizations because they are supportive of LGBT rights. A second measure asked participants the importance of their sexual identity ( $1=$ not at all, 5 = extremely). Next, participants were asked how many of their close friends are lesbian, gay, bisexual, or transgender to measure social integration ( 1 = some, most, or all).

Participants were asked about their relationship status and what the sex of their partner was. Participants can indicate that they were not currently in a relationship, in a relationship with a different-sex partner, or in a relationship with a samesex partner. Current relationship status is important for all respondents because others tend to categorize sexual minorities based on their partnership status; this is particularly true for bisexual individuals (Mize and Manago 2018). Because identity commitment has often been operationalized based on the number of important 
Table 2: Description of key variables.

\begin{tabular}{|c|c|c|}
\hline & $n$ & Proportion/Mean \\
\hline \multicolumn{3}{|l|}{ Sexual identity disclosure } \\
\hline Overall identity disclosure & 1,085 & 0.79 \\
\hline Out to mother & 976 & 0.61 \\
\hline Out to father & 853 & 0.47 \\
\hline Out at work & 702 & 0.51 \\
\hline LGBT involvement index (0-4) & 1,085 & 1.97 \\
\hline Importance of identity & 1,085 & \\
\hline Not at all important & & 0.12 \\
\hline Not too important & & 0.23 \\
\hline Somewhat important & & 0.28 \\
\hline Very important & & 0.25 \\
\hline Extremely important & & 0.12 \\
\hline Social integration & 1,085 & 0.61 \\
\hline Relationship status & 1,085 & \\
\hline Not a relationship & & 0.54 \\
\hline In a different-sex relationship & & 0.20 \\
\hline In a same-sex relationship & & 0.26 \\
\hline \multicolumn{3}{|l|}{ Perceived social acceptance of } \\
\hline Lesbian women & 1,078 & 0.89 \\
\hline Gay men & 1,079 & 0.79 \\
\hline Bisexual women & 1,079 & 0.80 \\
\hline Bisexual men & 1,077 & 0.53 \\
\hline
\end{tabular}

Notes: Standard deviation of LGBT involvement index $=1.60$. Optimally scaled values of importance of identity are $1.140,1.675,3.279,4.170$, and 4.469 .

others who depend on one's identity enactment (Brenner et al. 2014), we treat current relationship status as another indicator of social integration.

To gauge perceived social acceptance, participants were asked how much social acceptance they perceive in the United States today for gay men, lesbian women, bisexual men, and bisexual women ( $1=$ some, a lot). Importantly, these were asked as separate questions for each of the four sexual orientation groups (i.e., not about LGB individuals in general), and all four questions were asked of each participant, regardless of their sexual orientation identity.

Control variables. In all models, we included control variables for age, education, household income, race, marital status, parental status, employment status, urbanicity, and political ideology (see Table 1 for descriptive statistics of our control variables).

Missing data. Our sample started at 1,101 LGB men and women who had no missing data on any of our dependent variables or on sexual orientation identity (4.51 percent of cases were excluded for missing data on a dependent variable). We excluded a further 16 observations (1.45 percent of all cases) for missing data on one or more control variables for a final analytic sample of $1,085 .{ }^{5}$ The samples were smaller for the analyses about being out at work $(n=702)$, to their mother $(n=976)$, and to their father $(n=853)$ as these questions were not relevant to some 
individuals in the sample (e.g., those who are not working or do not have a living father figure).

\section{Analytic Strategy}

The analyses proceeded in three stages. First, we compared rates of sexual orientation identity disclosure using binary logistic regressions, testing Hypothesis 1. Second, we examined group differences in sexual minority involvement and perceived social acceptance, testing Hypotheses 2 and 4 and laying the groundwork for our mediation analyses. Social integration and social acceptance were modeled using logistic regression. The LGBT involvement index was modeled using negative binomial regression. Importance of identity was scaled using alternating least squares optimal scaling (ALSOS; Young 1981; Jacoby 1999), a method of empirically assigning meaningful units and spacing among categories of an ordinal variable, which was then modeled using linear regression. ${ }^{6}$ Additional details of the ALSOS method are described in the online supplement A. Third, we performed mediation analyses to determine what accounts for group differences in identity disclosure (described below), testing Hypotheses 3 and 5. Throughout, we presented average marginal effects (AME) - rather than coefficients—which summarize the effects of the independent variables in terms of their influence on the model predictions (Long and Freese 2014). ${ }^{7}$ All analyses included poststratification survey weights to account for nonresponse and noncoverage biases. ${ }^{8}$ All significance tests were two-tailed with significance assessed at the $p<0.05$ level unless otherwise noted.

\section{Results}

\section{Differences in Rates of Sexual Orientation Identity Disclosure}

Table 3 includes AMEs from binary logistic regressions of sexual orientation identity disclosure on sexual orientation identity group. For these analyses, the omitted category was lesbian women. For additional pairwise comparisons implicated in Hypothesis 1, we computed and compared predicted probabilities adjusted by the controls. For the key comparison between gay and bisexual men, we included a superscript $\left({ }^{a}\right.$ in Table 3 and ${ }^{e}$ in Table 4$)$ to indicate a significant difference between these two groups. Looking at the results from Table 3, it is clear that bisexual women and men were significantly less likely to disclose their sexual orientation identities to others compared with lesbian women $(p<0.001$ for all four measures of disclosure). For the most part, there were no differences between gay men and lesbian women; only for work settings was there a marginally significant difference with gay men slightly less likely to be out at work (AME $=-0.111, p=0.09$ ).

These differences were larger and significant when comparing bisexual men and women with their gay/lesbian counterparts. Figure 1 includes predicted probabilities for being out to important others, mothers, fathers, and coworkers by sexual orientation group. The predicted probability of a lesbian woman being out to at least some of the important people in her life was 0.946 , whereas a bisexual woman only had a 0.675 predicted probability of being out (difference of 0.271 , 
Table 3: Average marginal effects from binary logistic regressions of sexual identity disclosure on sexual identity group.

\begin{tabular}{lcccc}
\hline & Overall Disclosure & Out to Mother & Out to Father & Out at Work \\
\hline Bisexual women & $-0.271^{\dagger}$ & $-0.344^{\dagger}$ & $-0.288^{\dagger}$ & $-0.387^{\dagger}$ \\
Gay men & $(0.049)$ & $(0.059)$ & $(0.068)$ & $(0.065)$ \\
& $-0.035^{a}$ & $0.029^{a}$ & $0.025^{a}$ & $-0.111^{a}$ \\
Bisexual men & $(0.029)$ & $(0.048)$ & $(0.059)$ & $(0.065)$ \\
& $-0.560^{a}$ & $-0.479^{\dagger}$ & $-0.491^{\dagger}$ & $-0.616^{\dagger}{ }^{\dagger}$ \\
Age & $(0.067)$ & $(0.073)$ & $(0.072)$ & $(0.091)$ \\
& $<0.001$ & $-0.004^{*}$ & $-0.005^{*}$ & -0.002 \\
College degree & $(0.001)$ & $(0.002)$ & $(0.002)$ & $(0.002)$ \\
& 0.008 & -0.006 & -0.011 & 0.001 \\
Income & $(0.031)$ & $(0.041)$ & $(0.045)$ & $(0.049)$ \\
& $<-0.001$ & $<-0.001$ & $<0.001$ & $<0.001$ \\
White & $(<0.001)$ & $(<0.001)$ & $(0.001)$ & $(0.001)$ \\
& 0.036 & 0.075 & 0.093 & 0.057 \\
Parent & $(0.035)$ & $(0.046)$ & $(0.054)$ & $(0.058)$ \\
& 0.074 & $0.193^{\dagger}$ & 0.123 & -0.056 \\
Married & $(0.040)$ & $(0.048)$ & $(0.072)$ & $(0.083)$ \\
Employed & 0.003 & -0.008 & -0.074 & 0.055 \\
& $(0.043)$ & $(0.052)$ & $(0.066)$ & $(0.070)$ \\
Urban & 0.056 & 0.040 & 0.018 & \\
Political ideology & $(0.040)$ & $(0.046)$ & $(0.052)$ & 0.026 \\
& 0.006 & 0.040 & 0.119 & $(0.085)$ \\
$N$ & $(0.047)$ & $(0.065)$ & $(0.084)$ & 0.049 \\
& $0.045^{\dagger}$ & $0.057^{\dagger}$ & $0.077^{\dagger}$ & $(0.027)$ \\
\hline
\end{tabular}

Notes: Standard errors in parentheses. ${ }^{a}$ Indication that the predictions for gay and bisexual men are significantly different at $p<0.05 .+p<0.01 ; * p<0.05$ (two-tailed tests).

$p<0.001)$. Similarly, a gay man had a 0.911 predicted probability of being out to at least some of the important people in his life compared with—strikingly—only a 0.386 predicted probability of being out for a bisexual man (difference of 0.525 , $p<0.001$ ). As is clear in Figure 1, these patterns held for being out across all four domains assessed. Collectively, these findings suggest that the patterns observed in prior work hold in a national probability sample and across multiple domains. Consistent with Hypothesis 1, across domains of friendship, family, and work, bisexual men and women were significantly less likely to be out compared with their gay/lesbian counterparts.

\section{Strength of Sexual Identity and Self-Authenticity}

Having shown the substantively large and meaningful differences in the probability of sexual orientation identity disclosure between bisexual men and women and their gay/lesbian counterparts, we began to examine differences in factors that can theoretically explain these differences. Table 4 shows AMEs from regressions of 


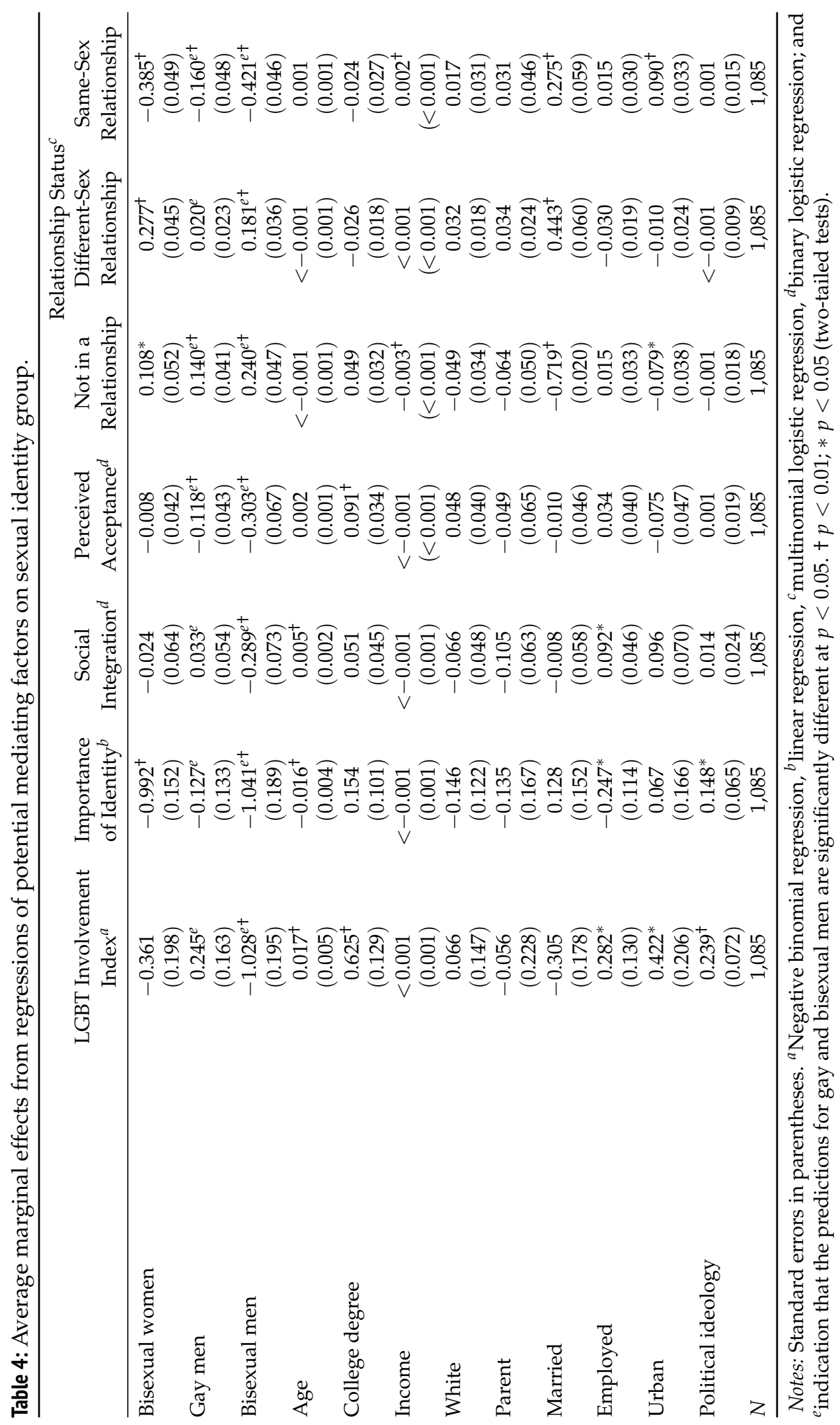




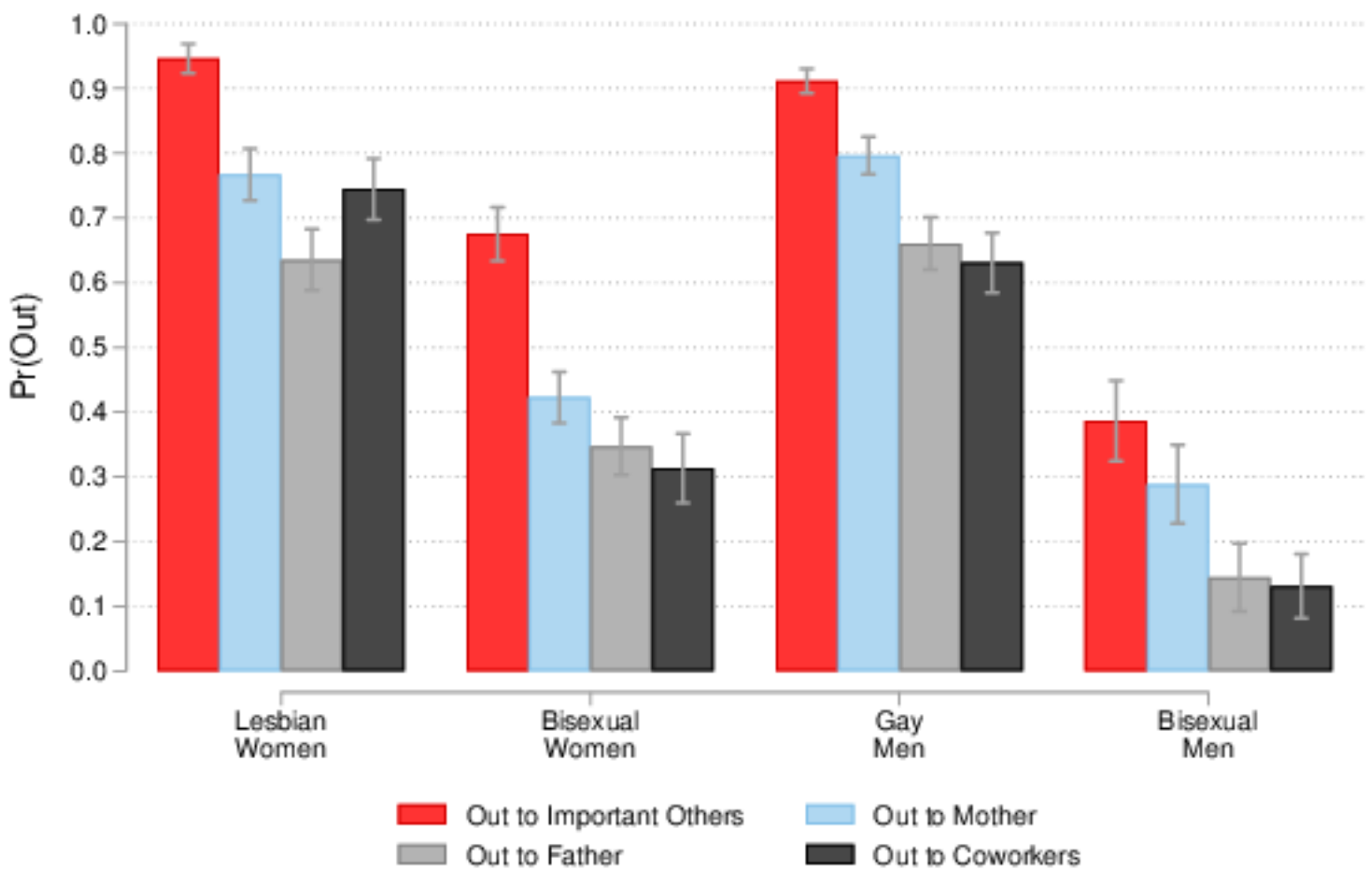

Figure 1: Predicted probability of sexual identity disclosure by group, across domains. Note: Error bars represent \pm 1 standard error of the predictions.

measures of identity integration (involvement index, importance of identity, social integration, and relationship status) as well as perceived social acceptance, which we examined in more detail in the next section. We found no differences between gay men and lesbian women for three of these first four outcomes. The exception was for relationship status (last three columns of Table 4) in which we observed that gay men were less likely to be in a relationship at all; and less likely to be in a same-sex relationship, compared with lesbian women (both marginal effects $p<0.001$ ). Turning to the contrasts between lesbian and bisexual women, we found that bisexual women report their sexual orientation identity is almost a point less important to them (on a five-point scale) than do their lesbian counterparts $(b=-0.992, p<0.001)$. Bisexual women were also more likely to not be in a relationship or in a different-sex relationship, and less likely to be in a same-sex relationship than lesbian women. Indeed, at a descriptive level, only 5 percent of bisexual women were partnered with another woman compared with 51 percent of lesbian women (patterns that were not explained by any of the model variables). Bisexual men reported that they were less involved in LGBT activities, viewed their sexual identity as a less important part of themselves, were less likely to have 
at least some close LGBT friends, and less likely to be in a same-sex relationship compared with lesbian women ( $p<0.001$ for all four outcomes).

We examined additional contrasts among groups by comparing the adjusted predictions across each outcome. Bisexual men participated in about one fewer LGBT activities compared with gay men $(p<0.001)$. In terms of the importance of their sexual identities, bisexual men viewed their identities as almost a point less important than their gay counterparts $(p<0.001)$. Bisexual men were also significantly less likely to have at least some LGBT friends. Compared with a predicted probability of 0.645 for gay men, bisexual men had a predicted probability of having at least some LGBT friends of only 0.323 (contrast $p<0.001$ ). In contrast, the difference in predicted probability between lesbian women (0.612) and bisexual women (0.588) for having LGBT friends was small and not statistically significant. Finally, only 2 percent of bisexual men were currently partnered with another man compared with 34 percent of gay men (with the vast majority of gay men reporting not being in a relationship).

Collectively, these findings suggest that bisexual women and men had less sexual orientation identity integration compared with their gay/lesbian counterparts in terms of importance of identity. In addition, bisexual men were less likely to be socially involved with LGBT-related activism and less socially integrated in terms of LGBT friendships and same-sex relationships. These negative effects suggested the importance of sexual orientation identity as a potential mediator to explain the gap in sexual orientation identity disclosure between bisexual and gay/lesbian individuals. Furthermore, LGBT involvement and social integration was another potential mediator for explaining the gap between bisexual and gay men.

\section{Prejudice toward Lesbian, Gay, and Bisexual Individuals}

Another theoretically important factor in potentially explaining the sexual identity disclosure gap was the perceived social acceptance of members of different sexual minority groups. Importantly, all participants were asked for the perceived social acceptance of all sexual minority groups (including their own). Figure 2 presents predicted probabilities of viewing each sexual orientation group as being accepted in society: each grouping is for perceptions of a certain LGB group; the separate bars represent the reported perceptions based on the sexual orientation identity of the respondent. For example, the first bar represents how lesbian women think lesbian women are viewed; the second bar how bisexual women think lesbian women are viewed; and so on. Several interesting patterns emerge. First, both lesbian and bisexual women were generally thought to be slightly more socially accepted than gay men. Second, bisexual men were thought to be the least socially accepted group - a view that is shared by all LGB groups surveyed.

Key to our argument is how participants viewed the social acceptance of their own group (e.g., how bisexual men think bisexual men are viewed; i.e., the last bar in Figure 1). Therefore, the perceived acceptance model in Table 4 examined differences in participants' perceived acceptance of members of their own group. As shown in the table, gay men had about a 0.118 lower probability of viewing their group as socially accepted compared with lesbian women $(p<0.01)$. This 


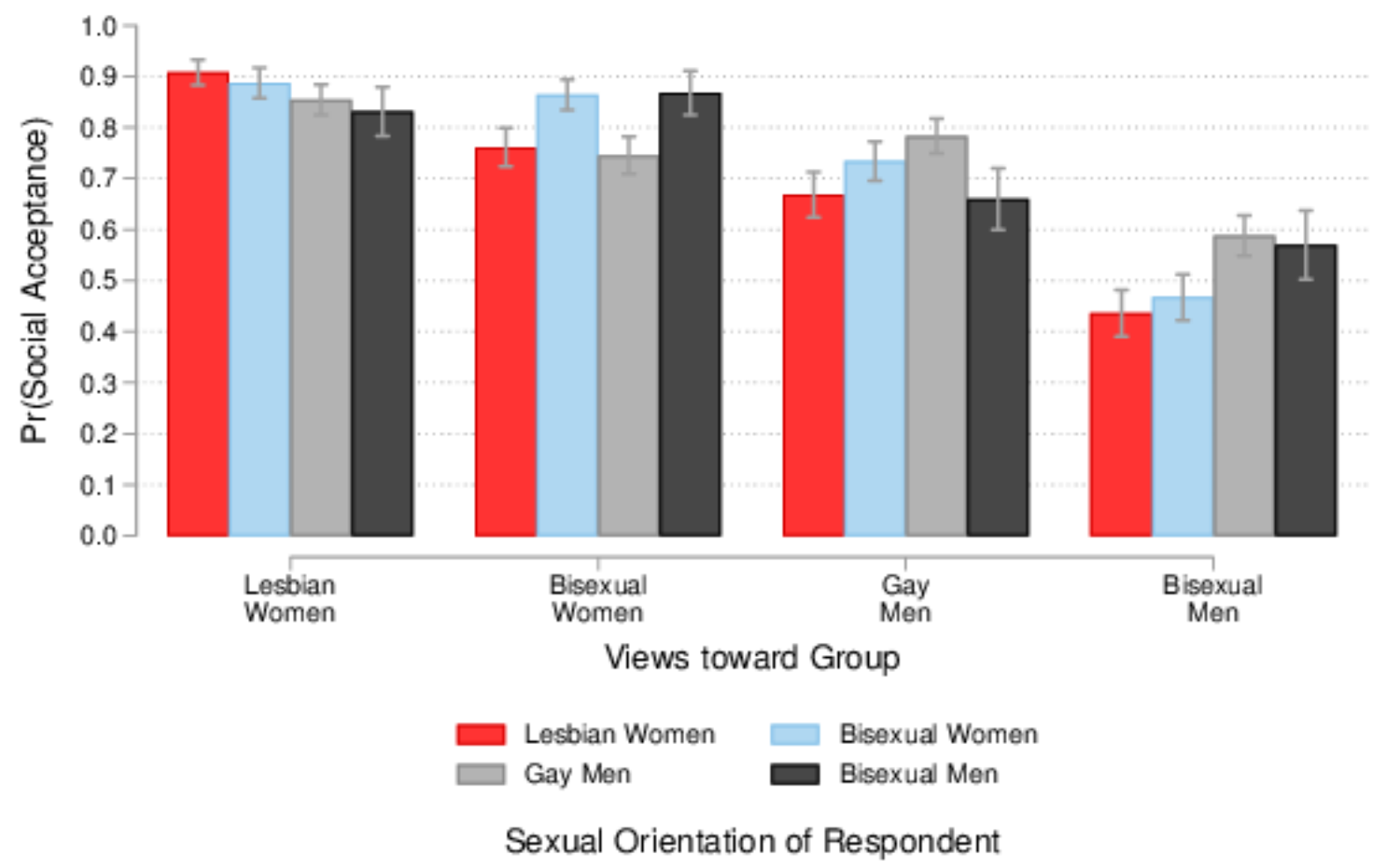

Figure 2: Predicted probability of viewing group as socially accepted (groupings represent perceptions of that group; separate bars are sexual orientation identity of the respondent). Note: Error bars represent \pm 1 standard error of the predictions.

was consistent with prior work comparing Americans' attitudes toward lesbian women and gay men (Doan et al. 2014; Doan, Miller, and Loehr 2015). In contrast, bisexual women viewed their group as similarly socially accepted to lesbian women $(\mathrm{AME}=-0.008 ; p=$ not significant).

Bisexual men were less likely to view their group as socially accepted compared with any other group. Bisexual men viewed less acceptance than lesbian women $(\mathrm{AME}=-0.303, p<0.001)$ and bisexual women (contrast $=-0.296, p<0.001)$. Among sexual minority men, gay men had a predicted probability of perceiving acceptance for other gay men of 0.773 , whereas bisexual men only had a predicted probability of perceiving acceptance of 0.588 (difference: $p=0.01$ ). This suggested that in addition to differences in identity integration, bisexual men (but not bisexual women) may be less likely to come out because of lower perceived social acceptance. The fact that there were more theoretically relevant factors at play for bisexual men compared with bisexual women could very well explain the larger gap in identity disclosure between bisexual and gay men than between bisexual and lesbian women. We formally assessed this as well as Hypotheses 2 to 5 in the next sections. 


\section{Mediation Analyses}

For our mediation analyses, we focused on overall sexual orientation identity disclosure. The results were substantively similar for other forms of disclosure (i.e., to their mother, father, or at work). To formally assess mediation, four conditions had to be satisfied: (1) the independent variable had to have a significant effect on the mediator (as shown in Table 4), (2) the independent variable had to have a significant effect on the dependent variable in the absence of the mediator (Table 3), (3) the mediator had to have a significant effect on the dependent variable (Table 5), and (4) the effect of the independent variable diminished upon the addition of the mediator to the model (Table 6; Baron and Kenny 1986). Testing for the fourth condition is relatively simple in linear regressions (e.g., Sobel 1982). However, it is more difficult in binary models because the size of the coefficient is reflective of not only explained variation of the independent variable but also the assumptions of the model and the error variation of the entire model (Breen, Karlson, and Holm 2013). To avoid this problem, we used a new technique involving comparisons of the marginal effect of the independent variable across models to formally test for mediation (Mize, Doan, and Long 2019). ${ }^{9}$ Marginal effects were appropriate summary effect measures for cross-model comparisons as they are unaffected by the problems described above for the coefficients (Long and Mustillo 2018; Mize 2019; Mize et al. 2019). Using this method, a significant reduction in the marginal effect (in terms of the probability of being out) after accounting for the effect of a mediator is evidence for mediation. In Table 6 we reported the percentage of the effect that was mediated, calculated as

$$
1-\frac{A M E_{\text {mediationmodel }}}{A M E_{\text {basemodel }}} \text {. }
$$

Table 5 includes results from a logistic regression of sexual identity disclosure on the identity integration measures and perceived social acceptance. Consistent with Hypotheses 2 and 4, all of our identity integration measures (involvement, importance, integration, relationship status) were significantly related to sexual identity disclosure $(p<0.001)$; the perceived social acceptance measure showed a marginally significant relationship with being out $(p=0.09)$. All of the effects are in the predicted directions (i.e., those with higher identity integration were more likely to be out; those who perceive more social acceptance of their identity were marginally more likely to be out).

Table 6 includes the AME of the difference in the probability of being out between lesbian and bisexual women (left side of table) and between gay and bisexual men (right side of table). Panel A of Table 6 shows the base model findings from our previous analyses indicating that bisexual women and men were significantly less likely to be out to at least some important people in their lives compared with their lesbian and gay counterparts (AME $=0.271$ and 0.525 , respectively; both $p<0.001$ ).

The first and third columns of Panel B of Table 6 show the size of the AME of being bisexual after taking into account each mediator. The second and fourth column reported the percentage reduction in the size of the effect after accounting for the mediator, along with stars to indicate whether the reduction is statistically significant. For women, importance of identity reduced the difference between 
Table 5: Average marginal effects from binary logistic regression of sexual identity disclosure on key variables.

\begin{tabular}{lc}
\hline & Overall Disclosure \\
\hline LGBT involvement index & $0.056^{\dagger}$ \\
Importance of identity & $(0.012)$ \\
& $0.033^{\dagger}$ \\
Social integration & $(0.013)$ \\
& $0.153^{\dagger}$ \\
In a different-sex relationship & $(0.029)$ \\
In a same-sex relationship & 0.039 \\
Perceived acceptance & $(0.062)$ \\
& $0.210^{\dagger}$ \\
Age & $(0.031)$ \\
College degree & 0.064 \\
& $(0.037)$ \\
Income & $<-0.001$ \\
White & $(0.001)$ \\
Parent & -0.049 \\
& $(0.036)$ \\
Married & $<-0.001$ \\
Employed & $(<0.001)$ \\
Urban & 0.036 \\
Political ideology & $(0.034)$ \\
Observations & $0.084^{*}$ \\
& $(0.042)$ \\
& -0.095 \\
& $(0.067)$ \\
& 0.041 \\
& $(0.035)$ \\
& -0.026 \\
& $(0.045)$ \\
& 0.029 \\
& $(0.020)$ \\
& 1,085 \\
\hline
\end{tabular}

Notes: Standard errors in parentheses. $+p<0.01 ; * p<0.05$ (two-tailed tests).

bisexual and lesbian women by 19 percent (reduction in $\mathrm{AME}=p<0.01$ ). Similarly, current relationship status also reduced the differences between bisexual and lesbian women by about 13 percent $(p<0.05)$. Taking all mediators into account, we found that 25 percent of the baseline difference between bisexual and lesbian women is mediated by the combination of identity factors and perceived social acceptance. It is important to note that although these factors reduced the gap between lesbian and bisexual women, none of them fully explained the difference in the probability of coming out across the two groups. These results were somewhat consistent with Hypothesis 3 (i.e., only some measures of identity integration mediate the differences between bisexual and lesbian women) and inconsistent with Hypothesis 5 (i.e., social acceptance does not mediate the differences between bisexual and lesbian women). 
Table 6: Average marginal effects of sexual orientation identity before (Panel A) and after (Panel B) accounting for various mediating variables.

\begin{tabular}{|c|c|c|c|c|}
\hline \multirow[t]{2}{*}{ Panel A: Base model } & \multicolumn{2}{|c|}{$\begin{array}{l}\text { Lesbian vs. Bisexual Women } \\
\text { AME }\end{array}$} & \multicolumn{2}{|r|}{$\begin{array}{c}\text { Gay vs. Bisexual Men } \\
\text { AME }\end{array}$} \\
\hline & \multicolumn{2}{|r|}{$\begin{array}{c}0.271^{+} \\
(0.049)\end{array}$} & & $\begin{array}{r}0.525^{+} \\
(0.065)\end{array}$ \\
\hline \multicolumn{5}{|l|}{ Panel B: Mediation models } \\
\hline & \multicolumn{2}{|c|}{ Lesbian vs. Bisexual Women } & \multicolumn{2}{|c|}{ Gay vs. Bisexual Men } \\
\hline & AME & $\%$ Reduction in $\mathrm{AME}^{a}$ & AME & $\%$ Reduction in $\mathrm{AME}^{a}$ \\
\hline \multicolumn{5}{|l|}{ Mediating variable } \\
\hline LGBT involvement & - & - & $\begin{array}{r}0.359^{+} \\
(0.066)\end{array}$ & $32 \%^{+}$ \\
\hline Importance of identity & $\begin{array}{r}0.217^{\dagger} \\
(0.046)\end{array}$ & $19 \%^{\dagger}$ & $\begin{array}{r}0.522^{+} \\
(0.071)\end{array}$ & $1 \%$ \\
\hline Social integration & - & - & $\begin{array}{r}0.428^{+} \\
(0.071)\end{array}$ & $19 \% *$ \\
\hline Relationship status & $\begin{array}{r}0.237^{+} \\
(0.046)\end{array}$ & $13 \% *$ & $\begin{array}{r}0.386^{\dagger} \\
(0.086)\end{array}$ & $26 \% *$ \\
\hline Perceived social acceptance & - & - & $\begin{array}{r}0.523^{+} \\
(0.066)\end{array}$ & $<1 \%$ \\
\hline All mediators & $\begin{array}{r}0.203^{+} \\
(0.040)\end{array}$ & $25 \% *$ & $\begin{array}{r}0.225^{\dagger} \\
(0.074)\end{array}$ & $57 \%^{+}$ \\
\hline
\end{tabular}

Notes: All models include controls for age, education, household income, race, marital status, parental status, employment status, urbanicity, and political ideology. Standard errors in parentheses. ${ }^{a}$ Significance test shown is from a test of the marginal effects across models $\left(\mathrm{AME}_{\text {basemodel }}-\mathrm{AME}_{\text {mediationmodel }}\right) .+p<0.01$; $* p<0.05$ (two-tailed tests).

A similar but stronger story emerged for men. Three of the four identity measures significantly mediated the difference between bisexual and gay men (involvement, integration, and relationship status; consistent with Hypothesis 3); however, importance of identity and perceived social acceptance did not (contrary to Hypothesis 5). The difference between the probability of gay and bisexual men disclosing their identity to important others was significantly reduced with the inclusion of LGBT involvement (32 percent reduction), social integration (19 percent reduction), and current relationship status (26 percent reduction; all reductions reported $p<0.05)$. Overall, when including all mediators, the identity integration measures mediated 57 percent of the difference between gay and bisexual men-though again, this did not explain the entire gap between gay and bisexual men.

\section{Discussion}

Sexual identity disclosure is an important decision that sexual minorities face. However, little was known about the prevalence of disclosure and the mechanisms through which people choose to disclose their sexual identities to others. Our 
results point to an inherent trade-off that sexual minorities face when deciding whether and to whom they disclose their sexual identity. Based on prior theoretical and empirical work, we derived five hypotheses to be tested in the analyses. Results support many but not all hypotheses.

In support of Hypothesis 1, we replicated and extended the external validity of prior work showing that bisexual women and men are significantly less likely than their gay/lesbian counterparts to disclose their sexual orientation identity to others. Although prior work has focused on specific domains of identity disclosure (Weinberg et al. 1994; Rodríguez Rust 2002; Herek et al. 2010), our results show, in a nationally representative sample, that bisexual men and women are less likely to disclose their identities across the major domains of social life-family, work, and friendship.

Likewise, we found support for Hypotheses 2 and 3, showing that measures of identity commitment and importance of identity significantly predict and mediate the gap in sexual identity disclosure. Drawing on social psychological work on identity confirmation (Burke and Stets 2009), these results demonstrate the value of bridging social psychology with work on sexuality. The patterns suggest that part of the reason that bisexual men and women are less likely to disclose their sexual identity is because their identities are less connected to sources of identity confirmation and appraisal via other LGBT individuals and activities. Likely because of this, bisexual men and women view their sexual orientation identity as a less important part of their lives. Past research demonstrates the lower levels of engagement bisexual men and women have with gay and lesbian organizing (McLean 2008; Thompson 2012; Hull and Ortyl 2013). Our results provide a theoretical implication for this lower engagement: lower identity commitment and lower likelihood of sexual identity disclosure.

Of course, because the data are cross sectional, we cannot rule out the alternative causal direction. It is possible that LGBT involvement, importance of sexual identity, and LGBT social integration are outcomes of sexual identity disclosure rather than causes of them. Recognizing this data limitation, our argument is correlational. Our theoretical framework implies the causal direction presented, but more work needs to be done to better understand the directionality of the relationship.

Contrary to our hypotheses, there is no significant evidence that perceived social acceptance of one's sexuality group is related to the decision to disclose one's identity. This is surprising in part because bisexual men view significantly less social acceptance of their group than do gay men. Importantly, we found there is broad consensus in terms of perceived social acceptance of all sexual orientation groups examined-that is, LGB individuals tend to agree how much each group is accepted in society-with agreement that lesbian women are the most socially accepted and bisexual men are the least socially accepted. Nevertheless, our results suggest that this awareness of the stigma of bisexuality is not a significant factor in people's decisions to come out.

Research has typically considered bisexual individuals with gay/lesbian individuals as a singular, homogenous LGB group. However, researchers are increasingly illustrating that bisexual men and women should be examined as a separate group and that combining them with other sexual minorities can produce misleading 
conclusions (Rodríguez Rust 2002; Worthen 2013; Mize 2016). We contribute to this growing literature by showing the differences in sexual orientation disclosure rates between bisexual individuals on the one hand and gay/lesbian individuals on the other. Importantly, our examinations focus on the mechanisms underlying this difference, which is a needed contribution as bisexual women and men are typically excluded from coming out studies (but see Scherrer, Kazyak, and Schmitz [2015]).

By treating sexual minorities as a heterogeneous group, important lessons can be learned. For example, we find that traditional theories explaining the identity disclosure process explains much more of the variation in men's disclosure decisions than women's decisions. Part of this is due to there being much more of a difference to be explained when comparing gay and bisexual men than there are between lesbian and bisexual women. Net of this, however, things like involvement and social integration significantly predicts disclosure for men, but not for women. This suggests that our current theorizing about sexuality and sexual identity processes may be ill-equipped to explain women's behaviors, so more research is needed to identify and test other potential mechanisms.

Beyond understanding the coming out process, especially among bisexual individuals, this article also speaks to issues of self-authenticity and identity commitment. Social psychologists have shown that theories of group threat (Doan et al. 2014), emotions (Doan et al. 2015), and stereotyping (Mize and Manago 2018) can be fruitfully applied to sexuality research. We extend these bridges by incorporating theories of self and identity (Stryker and Burke 2000; Burke and Stets 2009). In doing so, our findings show that identity concealment can be understood as identity nonverification. If so, future research can explore the implications of this identity nonverification for outcomes like mental health. For example, identity verification has positive consequences on self-esteem (Burke and Stets 1999), whereas nonverification is linked to distress (Burke and Harrod 2005).

The finding that perceived social acceptance has little effect on sexual minorities' decisions to come out can also be further explored in future research. Interview studies designed to capture the decision-making process can speak to why people may not focus on the potential stigma of their sexual identities-whether the desire for self-authenticity edge considerations of negative consequences or if some other reason, such as contextual factors, underlie this finding (Orne 2011).

Research on sexual prejudice remains important despite liberalizing attitudes toward sexual minorities. However, research on sexual prejudice generally assumes that an individual's sexual orientation is known to observers. This study shows that sexual identity disclosure should not be taken for granted and that the pathways through which identity disclosure occurs can aid in our understanding of sexual prejudice more broadly. By doing so, we can better understand how individuals negotiate the inherent trade-offs between managing stigma and sexual prejudice on the one hand and authenticity and identity verification on the other hand.

\section{Notes}

1 As we discuss later in the Background section, there are multiple dimensions of sexual orientation, including identity, attraction, and behavior. Our focus here is on sexual 
identity, in part, to be consistent with the bulk of the research on sexual orientation disclosure (McLean 2007).

2 We use the term "sexual minorities" to refer collectively to individuals with a nonheterosexual sexual orientation identity. We focus only on gay, lesbian, and bisexual individuals in this article, though we acknowledge additional sexual minority categories exist, and we expect the processes studied here may work differently for other groups.

3 Transgender men and women were also included in the Pew survey. We exclude these individuals from our presented analyses as the processes of disclosure, stigmatization, and discrimination for transgender individuals are theoretically distinct from those of LGB individuals.

4 It is possible that others may be "aware" of participants' sexual orientation identity due to implicit cues rather than disclosure per se, and we cannot dismiss that possibility. However, participants are unlikely to acknowledge that others are aware of their sexual orientation identity if they did not in some way disclose or confirm their sexual orientation identities to others. Partially because of this ambiguous wording, we also examine other social domains of identity disclosure where the survey question explicitly asks whether participants "told" their mother and father about their sexual identity.

5 We replicated all of the analyses here after using multiple imputation to preserve these 16 cases; all findings are substantively identical. We exclude these cases for the presented analyses as listwise deletion allows for much greater flexibility in the postestimation analyses we present throughout the article.

6 We use this strategy because importance of identity is used both as a dependent and an independent variable across various models; by optimally scaling the values, we are able to treat importance of an identity as a meaningful continuum in both settings.

7 The average marginal effects for all binary independent variables represent discrete changes (e.g., 1 vs. 0), whereas the average marginal effects for all continuous independent variables are for instantaneous changes (see Long and Freese 2014).

8 Upon acceptance, all data and coding files necessary to reproduce the analyses will be posted and publicly available via the authors' websites.

9 The method involves simultaneously estimating the two models (Weesie 2000) in order to facilitate statistical tests of effect sizes across multiple models-here, the effect of coming out in the base model compared with the effect of coming out in the mediation model (see Canette [2014] and Mize et al. [2019] for similar examples). As a robustness check, we also estimated linear probability models (Breen, Karlson, and Holm 2018). The substantive size of the effects are all but identical in the robustness checks. Exact details of the robustness checks and a table of the findings are reported in online supplement B.

\section{References}

Baron, Reuben M., and David A. Kenny. 1986. "The Moderator-Mediator Variable Distinction in Social Psychological Research: Conceptual, Strategic, and Statistical Considerations." Journal of Personality and Social Psychology 51(6):1173-82. https://doi.org/10.1037/ 0022-3514.51.6.1173.

Berg, Nathan, and Donald Lien. 2006. "Same-Sex Sexual Behaviour: US Frequency Estimates from Survey Data with Simultaneous Misreporting and Non-response." Applied Economics 38(7):757-69. https: //doi .org/10.1080/00036840500427114.

Bradford, Mary. 2004. “The Bisexual Experience: Living in a Dichotomous Culture." Journal of Bisexuality 4(1-2):7-23. https : //doi .org/10.1300/J159v04n01_02. 
Breen, Richard, Kristian Bernt Karlson, and Anders Holm. 2013. "Total, Direct, and Indirect Effects in Logit and Probit Models." Sociological Methods and Research 42(2):164-91. https : //doi.org/10.1177/0049124113494572.

Breen, Richard, Kristian Bernt Karlson, and Anders Holm. 2018. "Interpreting and Understanding Logits, Probits, and Other Nonlinear Probability Models." Annual Review of Sociology 44:39-54. https://doi .org/10.1146/annurev-soc-073117-041429.

Brenner, Philip S., Richard T. Serpe, and Sheldon Stryker. 2014. “The Causal Ordering of Prominence and Salience in Identity Theory: An Empirical Examination." Social Psychology Quarterly 77(3):231-52. https : //doi .org/10.1177/0190272513518337.

Burke, Peter J., and Jan E. Stets. 1999. "Trust and Commitment through Self-Verification." Social Psychology Quarterly 62(4):347-66. https : //doi .org/10. 2307/2695833.

Burke, Peter J., and Jan E. Stets. 2009. Identity Theory. Oxford: Oxford University Press. https://doi.org/10.1093/acprof: oso/9780195388275.001.0001.

Burke, Peter J., and Michael M. Harrod. 2005. “Too Much of a Good Thing?" Social Psychology Quarterly 68(4):359-74. https://doi.org/10.1177/019027250506800404.

Canette, Isabella. 2014. "Using gsem to Combine Estimation Results." STATA Blog. https : //blog.stata.com/2014/08/18/using-gsem-to-combine-estimation-results/.

Coffman, Katherine B., Lucas C. Coffman, and Keith M. Marzilli Ericson. 2017. "The Size of the LGBT Population and the Magnitude of Anti-Gay Sentiment Are Substantially Underestimated." Management Science 63(10):3147-528. https://doi.org/10.1287/ mnsc. 2016.2503.

Doan, Long, Annalise Loehr, and Lisa R. Miller. 2014. "Formal Rights and Informal Privileges for Same-Sex Couples: Evidence from a National Survey Experiment." American Sociological Review 79(6):1172-95. https ://doi .org/10.1177/0003122414555886.

Doan, Long, Lisa R. Miller, and Annalise Loehr. 2015. “The Power of Love: The Role of Emotional Attributions and Standards in Heterosexuals' Perceptions of Lesbian and Gay Couples." Social Forces 94(1):401-25. https://doi .org/10.1093/sf/sov047.

England, Paula, Emma Mishel, Mónica L. Caudillo. 2016. "Increases in Sex with Same-Sex Partners and Bisexual Identity across Cohorts of Women (but Not Men)." Sociological Science 3:951-70. https://doi .org/10.15195/v3.a42.

Erickson, Rebecca J. 1995. "The Importance of Authenticity for Self and Society." Symbolic Interaction 18(2):121-44. https://doi.org/10.1525/si.1995.18.2.121.

Erickson, Rebecca J., and Amy S. Wharton. 1997. "Inauthenticity and Depression: Assessing the Consequences of Interactive Service Work." Work and Occupations 24(2):188-213. https://doi.org/10.1177/0730888497024002004.

Gates, Gary J. 2011. How Many People Are Lesbian, Gay, Bisexual, and Transgender? Los Angeles: The Williams Institute.

Goffman, Erving. 1963. Stigma: Notes on a Spoiled Identity. Upper Saddle River, NJ: Prentice Hall.

Herek, Gregory M. 2002. “Heterosexuals' Attitudes toward Bisexual Men and Women in the United States." Journal of Sex Research 39(4):264-74. https://doi.org/10.1080/ 00224490209552150.

Herek, Gregory M., and Kevin A. McLemore. 2013. "Sexual Prejudice." Annual Review of Psychology 64:309-33. https://doi.org/10.1146/annurev-psych-113011-143826.

Herek, Gregory M., J. Roy Gillis, and Jeanine C. Cogan. 2009. “Internalized Stigma among Sexual Minority Adults: Insights from a Social Psychological Perspective." Journal of Counseling Psychology 56(1):32-43. https: //doi .org/10.1037/a0014672. 
Herek, Gregory M., Aaron T. Norton, Thomas J. Allen, and Charles L. Sims. 2010. “Demographic, Psychological, and Social Characteristics of Self-Identified Lesbian, Gay, and Bisexual Adults in a US Probability Sample." Sexuality Research and Social Policy 7(3):176-200. https://doi.org/10.1007/s13178-010-0017-y.

Hitlin, Steven. 2003. “Values as the Core of Personal Identity: Drawing Links between Two Theories of Self." Social Psychology Quarterly 66(2):118-37. https ://doi .org/10.2307/ 1519843.

Hull, Kathleen E., and Timothy Ortyl. 2013. "Same-Sex Marriage and Constituent Perceptions of the LGBT Rights Movement." Pp. 67-102 in The Marrying Kind?: Debating Same-Sex Marriage within the Lesbian and Gay Movement. Minneapolis: University of Minnesota Press. https://doi.org/10.5749/minnesota/9780816681716.003.0003.

Jacoby, William G. 1999. "Levels of Measurement and Political Research: An Optimistic View." American Journal of Political Science 43:271-301. https : //doi .org/10. 2307/2991794.

Kreuter, Frauke, Stanley Presser, and Roger Tourangeau. 2008. "Social Desirability Bias in CATI, IVR, and Web Surveys: The Effects of Mode and Question Sensitivity." Public Opinion Quarterly 72(5):847-65. https : //doi .org/10.1093/poq/nfn063.

Kricheli-Katz, Tamar. 2013. “Choice-Based Discrimination: Labor-Force-Type Discrimination Against Gay Men, the Obese, and Mothers." Journal of Empirical Legal Studies 10(4):670-95. https://doi.org/10.1111/jels.12023.

Laumann, Edward O., John H. Gagnon, Robert T. Michael, and Stuart Michaels. 1994. The Social Organization of Sexuality: Sexual Practices in the United States. Chicago: University of Chicago Press.

Legate, Nicole, Richard M. Ryan, and Netta Weinstein. 2012. "Is Coming Out Always a 'Good Thing'? Exploring the Relations of Autonomy Support, Outness, and Wellness for Lesbian, Gay, and Bisexual Individuals." Social Psychological and Personality Science 3(2):145-52. https : //doi .org/10.1177/1948550611411929.

Long, J. Scott, and Jeremy Freese. 2014. Regression Models for Categorical Dependent Variables Using Stata. 3rd ed. College Station, TX: Stata Press.

Long, J. Scott, and Sarah A. Mustillo. "Using Predictions and Marginal Effects to Compare Groups in Regression Models for Binary Outcomes." Sociological Methods and Research, first published on October 21, 2018 as https : //doi .org/10.1177\%2F0049124118799374.

Martell, Michael E. 2013. “Differences Do Not Matter: Exploring the Wage Gap for Same-Sex Behaving Men." Eastern Economic Journal 39(1):45-71. https://doi .org/10 .1057/eej . 2012.4.

Mason-Schrock, Douglas. 1996. "Transsexuals' Narrative Construction of the 'True Self."' Social Psychology Quarterly 59(3):176-92. https ://doi .org/10.2307/2787018.

McLean, Kirsten. 2007. "Hiding in the Closet?: Bisexuals, Coming Out and the Disclosure Imperative." Journal of Sociology 43(2):151-66. https://doi.org/10.1177/ 1440783307076893.

McLean, Kirsten. 2008. "Inside, Outside, Nowhere: Bisexual Men and Women in the Gay and Lesbian Community." Journal of Bisexuality 8(1-2):63-80. https://doi .org/10.1080/ 15299710802143174.

Meyer, Ilan H. 2003. "Prejudice, Social Stress, and Mental Health in Lesbian, Gay, and Bisexual Populations: Conceptual Issues and Research Evidence." Psychological Bulletin 129(5):674-97. https://doi.org/10.1037/0033-2909.129.5.674.

Miller, Carol T., and Brenda Major. 2000. "Coping with Stigma and Prejudice." Pp. 243-72 in The Social Psychology of Stigma. New York: The Guilford Press. 
Mishel, Emma, Paula England, Jessie Ford, Mónica L. Caudillo. 2020. “Cohort Increases in Sex with Same-Sex Partners: Do Trends Vary by Gender, Race, and Class?" Gender and Society 34(2):178-209. https : //doi . org/10.1177/0891243219897062.

Mize, Trenton D. 2015. "What Social Psychology Can Contribute to the Study of Sex, Gender, and Sexual Orientation." Sociological Compass 9(12):1066-81. https://doi .org/10.1111/ soc4.12331.

Mize, Trenton D. 2016. "Sexual Orientation in the Labor Market." American Sociological Review 81(6):1132-60. https://doi.org/10.1177/0003122416674025.

Mize, Trenton D. 2019. "Best Practices for Estimating, Interpreting, and Presenting Nonlinear Interaction Effects." Sociological Science 6:81-117. https://doi .org/10.15195/v6 . a4.

Mize, Trenton D., Long Doan, and J. Scott Long. 2019. "A General Framework for Comparing Predictions and Marginal Effects across Models." Sociological Methodology 49(1):152-89. https://doi.org/10.1177/0081175019852763.

Mize, Trenton D., and Bianca Manago. 2018. "The Stereotype Content of Sexual Orientation." Social Currents 5(5):458-78. https : //doi .org/10.1177/2329496518761999.

Mohr, Jonathan J., and Ruth E. Fassinger. 2006. "Sexual Orientation Identity and Romantic Relationship Quality in Same-Sex Couples." Personality and Social Psychology Bulletin 32(8):1085-99. https://doi .org/10.1177/0146167206288281.

Mohr, Jonathan J., and Aaron B. Rochlen. 1999. "Measuring Attitudes Regarding Bisexuality in Lesbian, Gay Male, and Heterosexual Populations." Journal of Counseling Psychology 46(3):353-69. https://doi.org/10.1037/0022-0167.46.3.353.

Morris, Jessica F., Craig R. Waldo, and Esther D. Rothblum. 2001. "A Model of Predictors and Outcomes of Outness among Lesbian and Bisexual Women." American Journal of Orthopsychiatry 71(1):61-71. https ://doi.org/10.1037/0002-9432.71.1.61.

Orne, Jason. 2011. "'You Will Always Have To “Out" Yourself': Reconsidering Coming Out through Strategic Outness." Sexualities 14(6):681-703. https://doi .org/10.1177/ 1363460711420462

Pew Research Center. 2013. “A Survey of LGBT Americans: Attitudes, Experiences, and Values in Changing Times." Pew Research Center. http://www . pewsocialtrends .org/ 2013/06/13/a-survey-of-lgbt-americans/.

Ragins, Belle Rose. 2004. "Sexual Orientation in the Workplace: The Unique Work and Career Experiences of Gay, Lesbian and Bisexual Workers." Research in Personnel and Human Resources Management 23:35-120. https://doi.org/10.1016/S0742-7301(04)23002-X.

Ragins, Belle Rose, Romila Singh, and John M. Cornwell. 2007. "Making the Invisible Visible: Fear and Disclosure of Sexual Orientation at Work." Journal of Applied Psychology 92(4):1103-18. https://doi.org/10.1037/0021-9010.92.4.1103.

Rodríguez Rust, Paula C. 2002. "Bisexuality: The State of the Union." Annual Review of Sex Research 13(1):180-240. https://doi .org/10.1080/10532528.2002.10559805.

Scherrer, Kristin S., Emily Kazyak, and Rachel Schmitz. 2015. “Getting 'Bi' in the Family: Bisexual People's Disclosure Experiences." Journal of Marriage and Family 77(3):680-96. https://doi.org/10.1111/jomf .12190.

Sobel, Michael E. 1982. "Asymptotic Confidence Intervals for Indirect Effects in Structural Equation Models." Sociological Methodology 13:290-312. https://doi.org/10.2307/ 270723.

Stets, Jan E., and Ryan Trettevik. 2014. "Emotions in Identity Theory." Pp. 33-49 in Handbook of the Sociology of Emotions: Volume II, edited by J. E. Stets and J. H. Turner. New York: Springer. https://doi.org/10.1007/978-94-017-9130-4_3. 
Stryker, Sheldon. 1980. Symbolic Interactionism: A Social Structural Version. Menlo Park, CA: Benjamin/Cummings Pub.

Stryker, Sheldon, and Peter J. Burke. 2000. "The Past, Present, and Future of an Identity Theory." Social Psychology Quarterly 63(4):284-97. https : //doi .org/10. 2307/2695840.

Thoits, Peggy A. 2011. "Resisting the Stigma of Mental Illness." Social Psychology Quarterly 74(1):6-28. https://doi.org/10.1177/0190272511398019.

Thoits, Peggy A. 2012. "Role-Identity Salience, Purpose and Meaning in Life, and WellBeing among Volunteers." Social Psychology Quarterly 75(4):360-84. https ://doi .org/ 10.1177/0190272512459662.

Thoits, Peggy A. 2016. “'I'm Not Mentally Ill': Identity Deflection as a Form of Stigma Resistance." Journal of Health and Social Behavior 57(2):135-51. https://doi.org/10. $1177 / 0022146516641164$.

Thoits, Peggy A., and Bruce G. Link. 2016. "Stigma Resistance and Well-being among People in Treatment for Psychosis." Society and Mental Health 6(1):1-20. https ://doi .org/10. $1177 / 2156869315591367$

Thompson, Beverly Y. 2012. “The Price of 'Community' from Bisexual/Biracial Women's Perspectives." Journal of Bisexuality 12(3):417-28. https: //doi . org/10 . 1080/15299716. 2012.702623.

Tilcsik, András, Michel Anteby, and Carly R. Knight. 2015. "Concealable Stigma and Occupational Segregation: toward a Theory of Gay and Lesbian Occupations." Administrative Science Quarterly 60(3):446-81. https : //doi .org/10.1177/0001839215576401.

Weesie, Jeroen. 2000. "Seemingly Unrelated Estimation and the Cluster-Adjusted Sandwich Estimator." Stata Technical Bulletin 9(52).

Weinberg, Martin S., Colin J. Williams, and Douglas W. Pryor. 1994. Dual Attraction. Understanding Bisexuality. Oxford: Oxford University Press.

Worthen, Meredith G. F. 2013. "An Argument for Separate Analyses of Attitudes toward Lesbian, Gay, Bisexual Men, Bisexual Women, MtF and FtM Transgender Individuals." Sex Roles 68:703-23. https ://doi .org/10.1007/s11199-012-0155-1.

Yost, Megan R., and Genea D. Thomas. 2012. “Gender and Binegativity: Men's and Women's Attitudes toward Male and Female Bisexuals." Archives of Sexual Behavior 41(3):691-702. https://doi .org/10.1007/s10508-011-9767-8.

Young, Forrest W. 1981. “Quantitative Analysis of Qualitative Data.” Psychometrika 46:357-88. https://doi.org/10.1007/BF02293796.

Acknowledgments: We thank Brian Powell, Lisa R. Miller, and Brian T. Connor for excellent suggestions on various drafts of this paper. Parts of this paper were presented at the Indiana University Social Psychology, Health, and the Life Course seminar and the 2017 ASA Meetings. We thank audience members in both venues for their valuable comments. We are also grateful to the Pew Research Center for collecting the data used in our analyses. Partial funding for open access was provided by the UMD Libraries' Open Access Publishing Fund. Opinions, findings, and conclusions presented in this paper are ours and do not necessarily represent the views of any of the organizations or individuals above.

Long Doan: Department of Sociology, University of Maryland. E-mail: longdoan@umd.edu.

Trenton D. Mize: Department of Sociology and Advanced Methodologies, Purdue University. E-mail: tmize@purdue.edu. 